\title{
Jenis Dan Struktur Tropik Level Ikan Di Danau Tempe Kabupaten Soppeng Propinsi Sulawesi Selatan
}

\author{
Types and Structures of Tropical Fish Levels in Tempe Lake, Soppeng Regency, South \\ llSulawesi Province \\ Nur Asia Umar ${ }^{1 *}$, Muh. Hatta ${ }^{2}$ \\ *Email: nurasia.umar@universitasbosowa.ac.id \\ ${ }^{1}$ Program Studi Budidaya Perairan, Fakultas Pertanian, Universitas Bosowa \\ ${ }^{2}$ Program Studi Ilmu Kelautan, Fakultas Ilmu Kelautan dan Perikanan, Universitas Hasanuddin
}

Diterima: 12 September 2021 / Disetujui: 24 Desember 2021

\begin{abstract}
ABSTRAK
Penelitian berjudul Jenis dan Struktur Trofik Level Ikan di Danau Tempe Kabupaten Soppeng Propinsi Sulawesi Selatan yang dilakukan selama 4 bulan penelitian (Februari, maret, April dan Juni) tahun 2017, bertujuan untuk mengetahui transfer energy di perairan Danau tempe berjalan sesuai dengan sistem jejaring makanan dan manfaat penelitian ini untuk pengelolaan dan pemanfaatan sumber daya ikan yang optimal dan berkelanjutan diperairan Danau Tempe. Hasil penelitian menujukkan bahwa struktur trifik level Beberapa ikan yang tertangkap di perairan Danau Tempe adalah minimum 2 dan maksimum berfarisasi menurut jenis ikan dan waktu pengamatan. Disimpulkan bahwa sumberdaya alam diperairan danau tempe berupa fitoplankton dan zooplankton sebagai produser primer dan consumer primer masih mendukung untuk tingkatan trofik diatasnya yaitu ikan
\end{abstract}

Kata Kunci: Struktur, Trofik, Level, Danau Tempe, Soppeng

\section{ABSTRACT}

South Sulawesi, which was conducted for 4 months of research (February, March, April and June) in 2017, aims to determine the transfer of energy in the waters of Lake Tempe runs according to the food network system and the benefits of this research for optimal and sustainable management and utilization of fish resources. in the waters of Lake Tempe. The results showed that the trific level structure of some fish caught in the waters of Lake Tempe was a minimum of 2 and a maximum of varying according to the type of fish and the time of observation. It was concluded that the natural resources in the waters of Lake Tempe in the form of phytoplankton and zooplankton as primary producers and primary consumers still support the higher trophic levels, namely fish.

Keywords: Structure, Trophy, Level, Tempe Lake, Soppeng

(c) () This work is licensed under Creative Commons Attribution License 4.0 CC-BY International license

\section{A. PENDAhUluan}

Keanekaragaman Ikan di Indonesia terkenal cukup tinggi, terutama ikan air tawar. Produksi terbesar ikan air tawar di Indonesia berasal dari Danau Tempe yang terletak di Propinsi Sulwesi Selatan, bahkan Danau Tempe pernah Menjadi urutan ketiga dunia dalam pruduksi ikan air tawar Nila memberikan kosntribusi sekitar 21,3 \%

tahun 2011posisi Indonesia tersebut masih dibawah Cina yang memberikan kosntrbusi sebsarat 38,7 \% disusul Mesir 21,9 \% (Fishstat FAO,2013).

Berdasarkan hal tersebut diatas maka banyak peneliti dan Beberapa instansi yang terkait untuk melakukan penelitian di danau 
tersebut untuk mengkaji Bioekologi dari Danau Tempe tersebut. Selain itu pula kekayaan hayati dari Danau Tempe ini menjadi sumber mata pencahariaan bagi masyarakat setmpat, mansyarakat tidak hanya tinggal disekitar danau tetapi juga mendirikan rumah di tengah danau. Bentuk kegiatan perikanan yang terlihat didaerah ini adalah kegiatan berupa penangkapan ikan yang dilakukan sepanjang tahun. Selain kegiatan penangkapan yang juga dilakukan oleh masyarakat setempat adalah membuka lahan untuk tambak dan sistem Mina Padi.

Tangkapan lebih yang dilakukan oleh masyarakat disekitar perairan Danau Tempe dapat mengakibatkan degradasi populasi yang berujung pada penurunan produksi . Jika tangkapan lebih dilakukan pada jenjang trofik yang lebih rendah maka kegiatan tersebut akan mengurangi transfer biomassa pada jenjang trofik yang lebih tinggi. Dalam kondisi seperti itu , produktivitas primer fitoplankton yang tinggipun tidak akan mampu mendukung jenjang trofik diatasnya (Kaswadji dkk,2009).

Penyebab penurunan produksi ikan air tawar di Danau Tempe telah banyak informasi yang didapatkan, dari beberapa hasil penelitian diataranya terjadi degradasi lingkungan, pencemaran dan blooming tanaman air. Akibat 3 kerusakan tersebut sehingga sangat mempengaruhi hasil tangkapan nelayan di perairan Danau Tempe.

Salah satu cara untuk mempertahankan keanekaragaman ikan dalam suatu ekosistim yaitu dengan melakukan penelitian struktur trofik level. Tingkatan trofik menggambarkan tahapan transfer material atau energi dari setiap tingkat atau kelompok ke tingkat berikutnya, yang dimulai dengan produsen primer, konsumen primer (herbivora), sekunder, tersier, dan predator puncak. Pada dasarnya tingkat trofik (trophic level) merupakan urutan tingkat pemanfaatan pakan atau material dan energi seperti yang tergambarkan oleh rantai makanan (food chain).

Berdasarkan uraian diatas dan fakta dilapangan bahwa penelitian tentang jenis dan struktur tropic level di perairan Danau Tempe masih kurang, olehnya kami melakukan penelitian dengan tujuan untuk mengetahui transfer energy di perairan Danau Tempe apakah berjalan sesuai dengan sistem jejaring makanan dan manfaat penelitian ini untuk pengelolaan dan pemanfaatan sumber daya ikan yang optimal dan berkelanjutan diperairan Danau Tempe

\section{B. METODE PENELITIAN}

Penelitian dilaksanakan selama 4 bulan yaitu Februari, Maret dan April dan 
Juni tahun 2017. Diperairan Danau Tempe Kab.Soppeng Propinsi Sulawesi Selatan

Metode yang dilakukan adalah metode observasi yaitu dengan cara melihat komposisi hasil tangkapan nelayan baik yang tertangkap di danau,rawa dan sungai.. dan diperoleh dari hasil pengamatan langsung (pengukuran morfologi dan pengukuran hasil tangkapan).Ada beberapa nelayan yang kami kunjungi dilapangan pada saat sore hari selama penelitian saat baru kembali dari menangkap kemudian kami identifikasi jenis jenis ikan.

Trofik level (jenjang trofik) ikan ditentukan berdasarkan jenis atau item makanannya menggunakan hasil analisis isi usus/lambung dan dihitung dengan soft ware Trophlab2K.

Prinsip kerja soft ware ini adalah menghitung nilai trofik level berdasarkan kehadiran item makanan pada setiap individu sehingga diperoleh nilai trofik level dan standard error (Troph \pm s.e) per individu. Selanjutnya dari nilai individu setiap sampel satu spesies dalam setiap bulan dirata-ratakan sehingga di peroleh nilai trofik level ke-enam spesies yang dominan di dapatkan di perairan Danau tempe selama bulan Februari, Maret, April dan Juni sesuai dengan sampel analisis isi lambung ikan.

\section{HASIL DAN PEMBAHASAN}

\section{Jenis Ikan Tertangkap}

Jenis jenis ikan yang tertangkap selama penelitian ditemukan ada 13 jenis ikan yang bisa dilihat pada Tebel 1. Tabel 1 di atas terlihat bahwa ada 14 jenis ikan yang tertangkap selama penelitian, dari Beberapa data dan informasi sebelumnya ikan Sapu Sapu (Hypostomus plecostamus) adalah jenis ikan yang akhir akhir ini banyak terdapat di danau tersebut. Ikan ini kurang diminati oleh masyarakat sekitar perairan Danau Tempe karena selain bentuknya yang seperti tokek juga kulitnya sangat keras. 13 Jenis ikan lainnya adalah ikan yang masih diminanti oleh masyarakat sekitarnya dan masih sering tertangkap tetapi produksi sudah mulai menurun.

Untuk lebih Jelasnya ikan yang tertangkap tersebut dapat dilihat pada Gambar 1.

Tabel 1. Jenis Jenis Ikan Yang Tertangkap Selama Penelitian

\begin{tabular}{c|c|c|c}
\hline \multirow{2}{*}{ No } & \multicolumn{3}{|c}{ Jenis Ikan } \\
\cline { 2 - 4 } & Nama Latin & Nama Indonesia & Nama Daerah \\
\hline 1 & Puntius Javanicus & Tawes & Kandea \\
2 & Trichogaster pectoralis & Sepat siam & Camban \\
3 & Oreochromis niloticus & Nila & Kamboja \\
4 & Oreochromis mossambicus & Mujair & Mujair/jabir \\
5 & Anabas testudineus & Betok & Ceppe/Oseng \\
6 & Channa striata & Gabus & Bale bolong \\
7 & Osteochillus hasselti & Nilem & Turis \\
8 & Anguilla marmorata & Sidat & Masapi \\
9 & Glossogobius giuris & Bloso & Bungo \\
10 & Leognathus dussumieri & Bete & Bete \\
11 & Megalops cyprinoides & Bandeng laki & Kanpulan \\
12 & Cyprinus carprio & Mas & Bale ulaweng \\
13 & Monopterus albus & Belut & Lending/Lenro \\
14 & Hypostomus plecostamus & Ikan sapu sapu & Bale tokke \\
\hline
\end{tabular}




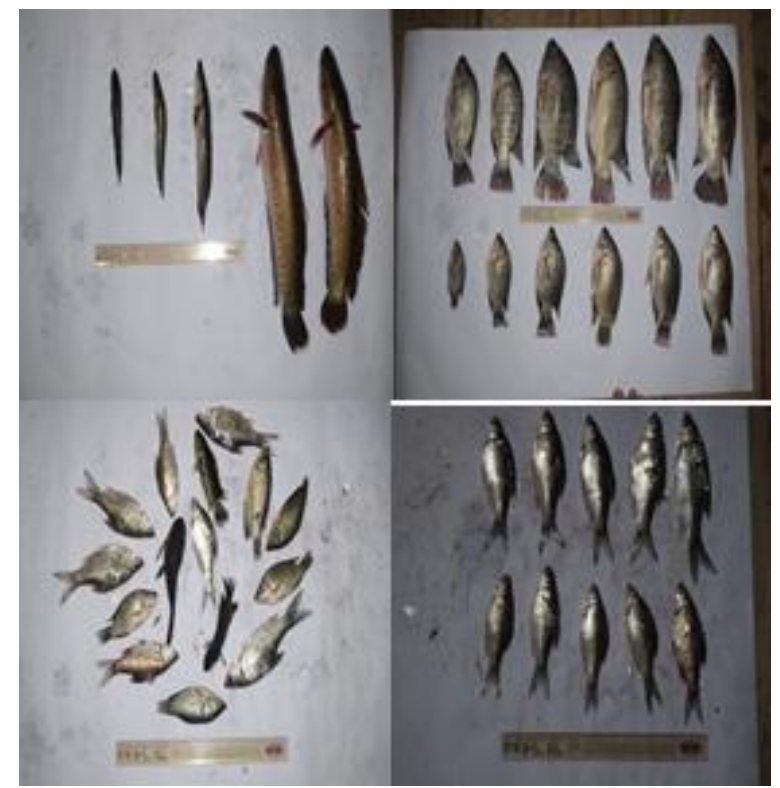

Gambar 1. Jenis Jenis Ikan Yang Tertangkap Selama Penelitian

\section{Struktur Trofik Level (Jenjang Trofik)}

Kisaran dan rata-rata trofik level selama 4 bulan pengamatan 6 jenis memperlihatkan bahwa nilai minimum trofik level ikan Sepat Siam, Nila, Mas, Tawes dan Betok yang tergolong herbivor, planktivor dan ominivor seraqgam yaitu 2.00 sedangkan nilai maksimum bervariasi antara jenis ikan dan waktu pengamatan. Berbeda dengan ikan gabus yang tergolong sebagai ikan karbivor nilai minimum trofik level yang terhitung selama pengamatan adalah 3.06. Nilai trofik level sebesar 2.00 yang didapatkan pada 5 jenis ikan terhitung ketika item makanan yang didapatkan dalam usus atau lambungnya terdiri dari tanaman air, detritus dan plankton. Kisaran dan ratarata nilai trofik level 6 jenis ikan yang dominan didapatkan selama 4 bulan pengamatan dirangkum dalam Tabel 2.

Tabel 2. Kisaran dan Rata-Rata Trofik Level Selama 4 Bulan Pengamatan 6 Jenis Ikan Yang Dominan Tertangkap di Danau Tempe

\begin{tabular}{c|l|c|c|c|c}
\hline \multicolumn{1}{c|}{ Jenis Ikan } & Kisaran dan Rata-Rata & Pebruari & Maret & April & Juni \\
\hline \multirow{3}{*}{ Ikan Mas } & Minimum & 2.00 & 2.00 & 2.00 & 2.00 \\
& Maksimum & 3.60 & 3.50 & 3.60 & 3.60 \\
& Rata-rata \pm s.e & 2.68 & 2.58 & 2.61 & 2.54 \\
\hline \multirow{3}{*}{ Ikan Gabus } & Minimum & 3.06 & 3.50 & 3.06 & 3.06 \\
& Maksimum & 4.50 & 4.50 & 4.50 & 4.50 \\
& Rata-rata \pm s.e & 3.69 & 3.66 & 3.75 & 3.52 \\
\hline \multirow{3}{*}{ Ikan Sepat Siam } & Minimum & 2.00 & 2.00 & 2.00 & 2.00 \\
& Maksimum & 3.20 & 3.20 & 3.20 & 3.20 \\
& Rata-rata \pm s.e & 2.41 & 2.40 & 2.31 & 2.27 \\
\hline \multirow{3}{*}{ Ikan Nila } & Minimum & 2.00 & 2.00 & 2.00 & 2.00 \\
& Maksimum & 3.40 & 3.40 & 3.40 & 3.06 \\
& Rata-rata \pm s.e & 2.45 & 2.57 & 2.38 & 2.34 \\
\hline \multirow{3}{*}{ Ikan Betok } & Minimum & 2.00 & 2.00 & 2.00 & 2.00 \\
& Maksimum & 3.50 & 3.40 & 3.50 & 3.50 \\
& Rata-rata \pm s.e & 2.96 & 2.95 & 3.08 & 2.85 \\
\hline \multirow{3}{*}{ Ikan Tawes } & Minimum & 2.00 & 2.00 & 2.00 & 2.00 \\
& Maksimum & 3.40 & 3.40 & 3.40 & 3.40 \\
& Rata-rata \pm s.e & 2.60 & 2.62 & 2.47 & 2.37 \\
\hline
\end{tabular}

Dalam Tabel 2. terlihat bahwa ikan Sepat Siam yang tergolong ikan herbivor memiliki nilai maksimum trofik level 3.20 dengan rata-rata yang relatif rendah dibandingkan dengan jenis ikan lainnya. Variasi antar waktu pengamatan juga tidak menunjukkan perbedaan yang signifikan dari bulan ke bulan. Hal ini disebabkan karena perhitungan nilai trofik level untuk item makanan dari tumbuhan dan fitoplankton maka pemangsanya hanya memiliki nilai 2.00 karena nilai trofik tanaman air dan fitoplankton hanya 1.00 sehingga nilai trofik pemangsa di atasnya adalah 2.00. Adanya variasi nilai melebihi 2.00 disebabkan karena selain mengkonsumsi tanaman air dan plankton juga terdapat cacing dan jenis makanan lainnya sehingga maksimum dapat mencapai lebih dari 2.00 . 
Ikan Tawes sebagai ikan planktivor yang mengkonsumsi item makanan lainnya seperti insekta dan plankton invertebrata lainnya memiliki nilai trofik level sedikit lebih tinggi dibandingkan dengan ikan Sepat Siam. Karena item makanan berupa plankton yang cenderung berubah dengan berubahnya kondisi lingkungan menyebabkan variasi antar waku pengamatan relatif lebih besar dibandingkan dengan ikan sepat siam meskipun nilai minimum dan maksimumnya lebih homogen.

Ikan Mas dan ikan Nila yang tergolong ikan omnivor memiliki overlap item makanan yang tinggi namun kecenderungan ikan Nila yang mengkonsumsi tanaman air menyebabkan lebih bervariasinya nilai trofik level dibandingkan dengan ikan Mas. Pada waktu permukaan air naik maka pola makan ikan nila yang banyak mencari makanan berupa tanaman di tepi menyebabkan menurunnya nilai trofik level pada saat tersebut. Berbeda dengan ikan Mas yang memiliki spektrum makanan yang lebih luas dengan komposisi yang relatif stabil dan seimbang antar item menyebabkan perubahannya lebih sedikit dan cenderung lebih tinggi jika dibandingkan dengan ikan nila.
Ikan omnivor lainnya yang cenderung karnivor yaitu ikan Betok merupakan ikan yang memiliki item makanan yang paling beragam diantara ikan omnivor lainnya yaotu ikan Nila dan ikan Mas. Kemunculan item makanan berupa insekta, molluska, larva/telur ikan dan larva invertebrata lainnya menyebabkan nilai trofik levelnya lebih tinggi dibandingkan dengan kedua jenis ikan omnivor lainnya. Adaptasi yang tinggi terhadap berbagai kondisi lingkungan memungkinkan ikan Betok untuk memakan berbagai item makanan yang ada di setiap habitat dan hal ini menyebabkan lebih stabilnya nilai trofik level dari waktu ke waktu.

Ikan Gabus yang tergolong ikan karnivor merupakan ikan predator air tawar yang mengkonsumsi berbagai jenis ikan dan nekton lainnya memiliki nilai trofik level yang lebih tinggi dibandingkan dengan kelima henis ikan lainnya yang diamati. Kebiasaan ikan gabus yang menguasai wilayah territorial tertentu berpengaruh terhadap kebiasaan makanannya yang cenderung stabil. Kestabilan ini disebabkan karena kemampuannya untuk memangsa dengan morfologi dan kelengkapan organ berupa gigi dan mulut yang mendukung untuk meangsa nekton lainnya menyebabkan ikan ini cenderung mendapatkan makanannya selama ikan lain 
dan nekton lainnya masih tersedia dalam perairan.

Nilai trofik level ikan berdasarkan waktu pengamatan menunjukkan adanya variasi antara jenis ikan. Ikan sepat siam dan memperlihatkan perubahan yang sangat kecil dari waktu ke waktu sedangkan ikan nila dan ikan tawes menunjukkan perubahan yang lebih besar dengan kecenderungan meningkat pada bulan Maret. Ikan mas, betok dan gabus memperlihatkan pola yang sama dimana kecenderungan meningkat di bulan April lalu menurun pada bulan Juni meskipun perubahannya tidak besar. Dinamika nilai trofik level ikan selama bulan Pebruari, Maret, April dan Juni ditunjukkan dalam Gambar 2.

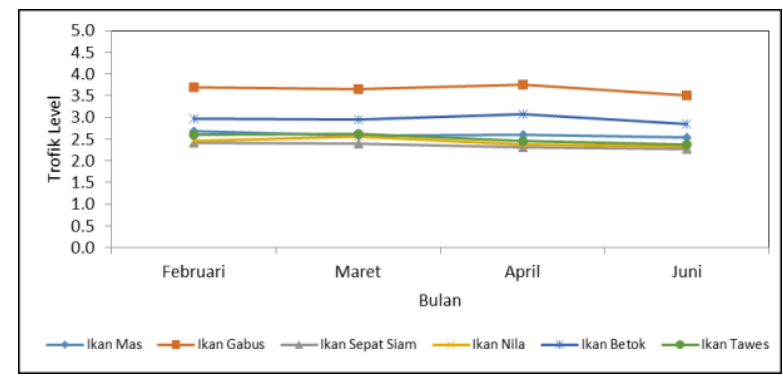

Gambar 2. Rata-Rata Trofik Level Selama 4 Bulan Pengamatan 6 Jenis Ikan yang Dominan Tertangkap di Danau Tempe

Pola umum dengan kecenderungan menurunnya nilai trofik level semua jenis ikan pada bulan Juni disebabkan karena pada saat tersebut terjadi puncak musim hujan dengan volume air Danau Tempe mencapai maksimum. Kondisi ini menyebabkan ikan herbivor dan ikan omnivor seperti ikan Sepat Siam, Nila, Mas dan Betok lebih banyak mengkonsumsi tanaman air di tepi danau. Disamping itu item makanan lainnya seperti insekta dan larva invertebrata lainnya agak sulit untuk dimangsa karena peluang bertemunya antara mangsa dan pemangsa menjadi lebih kecil pada saat volume air lebih tinggi. Demikian pula dengan ikan Gabus yang bersifat karnivor mengalami penurunan dalam memangsa nekton dan jenis ikan lainnya karena bantak bermigrasi mencari makanan ke tepi danau.

\section{KESIMPULAN DAN SARAN}

Hasil penelitian dan pembahasan dapat ditarik kesimpulan bahwa nilai struktur trofik level dari masing masing ikan yang tertangkap dapat disimpulkan bahwa Perairan Danau Tempe tingkatan trofik yang paling rendah yakni fitoplankton dan zooplankton masih sangat mendukung kehidupan untuk organisme tingkat trofik yang lebih tinggi yaitu ikan.

Selain struktur tofik level perairan Danau Tempe yang diteliti perlu juga melakukan penelitian yang lebih rinci tentang bioekologi secara bersamaan agar informasi tentang degradasi lingkungan dan populasi ikan dapat terjelaskan dengan baik

\section{DAFTAR PUSTAKA}

Budi, S., \& Aslamsyah, S. (2011). Improvement of the Nutritional Value and Growth of Rotifer (Brachionus plicatilis) by Different Enrichment Period with 
Bacillus sp. Jurnal Akuakultur Indonesia, 10(1), 67-73.

Budi, S., \& Zainuddin, Z. (2012). Peningkatan Asam Lemakrotifer Brachionus Plicatilis Dengan Periode Pengkayaan Bakteri Bacillus Sp. Berbeda. Octopus: Jurnal Ilmu Perikanan, 1(1), 1-5.

Budi, S., Djoso, P. L., \& Rantetondok, A. (2017, March). Tingkat dan Organ Target Serangan Ektoparasit Argulus sp. Pada ikan Mas Cyprinus carpio di Dua Lokasi Budidaya Di Kabupaten Gowa, Sulawesi Selatan. In Prosiding Forum Inovasi Teknologi Akuakultur (Vol. 1, No. 1, pp. 939-944).

Budi, S., Karim, M. Y., Trijuno, D. D., Nessa, M. N., \& Herlinah, H. (2018). Pengaruh Hormon Ecdyson Terhadap Sintasan Dan Periode Moulting Pada Larva Kepiting Bakau Scylla olivacea. Jurnal Riset Akuakultur, 12(4), 335-339.

Budi, S., Mardiana, M., Geris, G., \& Tantu, A. G. (2021). Perubahan Warna Ikan Mas Cyprinus carpio Dengan Penambahan Ekstra Buah Pala Myristica Argentha Pada Dosis Berbeda. Jurnal Ilmiah Ecosystem, 21(1), 202-207.

Budi, S., \& Mardiana, M. (2021). Peningkatan Pertumbuhan Dan Kecerahan Warna Ikan Mas Koi Cyprinus Carpio Dengan Pemanfaatan Tepung Wortel Dalam Pakan. Journal of Aquaculture and Environment, 3(2), 46-50.

E. Almohdar1* , F. N. J Souisa1. 2017. Komposisi Jenis Dan Tingkat Trofik (Trophic Level) Hasil Tangkapan Bagan Di Perairan Desa Ohoililir, Kabupaten Maluku Tenggara . p-ISSN 2550-1232 eISSN 2550-0929. CJurnal Sumberdaya Akuatik Indopasifik, Vol. 1 No. 2 November 2017

Hatta,M. 2014. Struktur Trofik Level Ikan Pelagis yang Dominan Tertangkap Bagan Rambo di Perairan Pantai Kabupaten Barru Selat, Makassar. OMNI Akuatika, Jurnal Penelitian Perikanan dan Kelautan, Vol. XII No. 16 Mei 2013. ISSN : 1858-3873

Kaswadji R, Hatta M, Umar NA. 2009. Penyusunan Model untuk Penangkapan Berkelanjutan Ikan Pelagis dengan Pendekatan Jenjang Trofik di Selat
Makassar. Jurnal Natural Indonesia 12:1 hal

Nasrur,R.Y. 2016. Keanekaragaman Ikan Air Tawar Di Perairan Danau Tempe Fakultas Sains Dan Teknologi Uin Alauddin Makassar. SKRIPSI

NA Umar, S Mulyani, I Suryani, M Hatta..2017. Model And Simulation Of Relationship Tropodinamik Waters Of Lake Tempe Wajo Disctrit.Proceeding Internasinal ISBN : 978-602-60736-1-7 ADRI..

Samuel, Safranmakmur Dan Petrus Rani Pongmasak ., 2012. Status Trofik Dan Estimasi Potensi Produksi Ikan Di Perairan Danau Tempe, Sulawesi Selatan.Jurnal Bawal.Vol.4 (2) Agustus 2012.

Yunus, A. R., Budi, S., \& Salam, S. (2019). Analisis Kelayakan Lokasi Budidaya Metode Karamba Jaring Apung Di Perairan Desa Pulau Harapan Sinjai. Journal of Aquaculture and Environment, 2(1), 1-5.

Yusneri, A., Budi, S., \& Hadijah, H. (2020). Pengayaan Pakan Benih Rajungan (Portunus Pelagicus) Stadia Megalopa Melalui Pemberian Beta Karoten. Journal of Aquaculture and Environment, 2(2), 39-42.

Yusneri, A., \& Budi, S. (2021, May). Blue swimming crab (Portunus pelagicus) megalopa stage seed feed enrichment with beta carotene. In IOP Conference Series: Earth and Environmental Science (Vol. 763, No. 1, p. 012026). IOP Publishing.

Wahyuni, S., Budi, S., \& Mardiana, M. (2020). Pengaruh Shelter Berbeda Terhadap Pertumbuhan Dan Sintasan Crablet Kepiting Rajungan (Portunus pelagicus). Journal of Aquaculture and Environment, 3(1), 06-10. 